\title{
Psychological Factors Associated with Response to Treatment in Rheumatoid Arthritis
}

\author{
Santiago T. ${ }^{1}$, Geenen R. ${ }^{2}$, Jacobs J.W.G. ${ }^{3}$ and Da Silva J.A.P. ${ }^{1 *}$ \\ ${ }^{1}$ Rheumatologist, Rheumatology Unit. Centro Hospitalar e Universitário de Coimbra, Portugal; ${ }^{2}$ Psychologist, Department of Clini- \\ cal and Health Psychology, Utrecht University, Utrecht, The Netherlands; ${ }^{3}$ Rheumatologist, Department of Rheumatology \& Clinical \\ Immunology, University Medical Center Utrecht, The Netherlands
}

\begin{abstract}
This paper presents a comprehensive review of research relating psychological domains with response to therapy in patients with rheumatoid arthritis. A holistic approach to the disease was adopted by incorporating not only disease activity but also dimensions of the impact of disease on patients' lives. Psychological distress, including depression and anxiety, is common among patients with rheumatoid arthritis and has a significant negative impact on response to therapy and on patients' abilities to cope with chronic illness. Evidence regarding the influence of positive psychological dimensions such as acceptance, optimism, and adaptive coping strategies is scarce. The mechanisms involved in these interactions are incompletely understood, although changes in neuro-endocrine-immune pathways, which are common to depression and rheumatoid arthritis, seem to play a central role. Indirect psychological influences on therapeutic efficacy and long-term effectiveness include a myriad of factors such as adherence, placebo effects, cognition, coping strategies, and family and social support. Data suggest that recognition and appropriate management of psychological distress may improve response to treatment and significantly reduce disease burden.
\end{abstract}

Keywords: Psychological factors, depression, coping, treatment, rheumatoid arthritis, placebo, psychological adjustment, psychoneuroimmunology.

\section{INTRODUCTION}

The prevalence of clinical depression and anxiety in patients with rheumatoid arthritis (RA) is almost double that of the general population. After adjustment for gender, age, marital status, income, and health conditions other than RA, the estimated odds ratio of depression is $1.63(95 \% \mathrm{CI}, 1.43-1.87)$ for patients with RA, compared to the general population [1]. When clinical depression and self-reported measures of depressive mood are included in estimates, prevalence has been shown to be $13-42 \%$ in patients with RA, and the condition is often unrecognized and undertreated [2, 3, 4]. Anxiety is also 2 to 4 times more prevalent in RA than in the general population and often overlaps with depression [5]. The impact of psychological distress on response to treatment in RA is increasingly recognized $[2,6,7]$, thus generating renewed interest in the psychological factors associated with response to treatment. The mechanisms underlying these factors remain largely unclear. However, given that similar biological systems and mediators are involved in psychological distress and inflammation, ample and complex opportunities for bidirectional interaction arise [8, 9]. Psychological distress can affect disease activity and response to treatment by altering the functioning of the immune, endocrine, and central nervous systems.

Health behavior is another vast field encompassing potential psychological influence on response to treatment and comprises factors such as adherence, smoking, exercise, obesity, visits to the doctor, and cognition, all of which affect pain and other parameters of disease activity and impact. Knowing and understanding the influence of psychological factors underlying response to treatment and the mechanisms involved could provide important information for selection of therapy, evaluation of response, and even targeted psychological interventions aimed at optimizing patient outcome. In this paper, we review the evidence for an association between psychological factors and response to treatment in RA. The review addresses 3 issues: 1) evidence for psychological factors that affect

*Address correspondence to this author at the Department, Serviço de Reumatologia, Centro Hospitalar e Universitário de Coimbra, 3000-076 Coimbra, Portugal; Fax: +351 239400587; E-mail: jdasilva@huc.min-saude.pt the response to treatment in RA, 2) potential mechanisms underlying these factors, and 3 ) interventions used to benefit the patient.

\section{EVIDENCE FOR PSYCHOLOGICAL FACTORS AF- FECTING RESPONSE TO TREATMENT IN RA}

\section{A. Depression, Anxiety, and Efficacy of Therapy}

The best evidence for the effect of emotions on response to treatment is provided by randomized control trials, in which potential confounders, such as adherence and expectations, are randomly distributed. The COMET [COmbination of Methotrexate (MTX) and ETanercept (ETN)] trial compared the effects of methotrexate with and without etanercept in 542 patients with RA. A report on this study published in 2011 analyzed 389 patients with data from the Hospital Anxiety and Depression Scale at baseline and subsequent visits during the 2 years of follow-up [10]. Among patients who had symptoms of depression or anxiety at baseline, significantly fewer had clinical remission, low disease activity, and normal functioning at the 2-year follow-up, even after correction for baseline disease activity levels. The bidirectional nature of these factors is highlighted by the observation that patients who achieved clinical remission less frequently had persistent symptoms of depression or anxiety compared with non-remitters. The relationship between baseline depression and objective outcome measures was not only driven by tender joint count or patient global health reports, which might be considered more prone to psychological influence, but also by correlations between depression and (more) objective measures (ie, erythrocyte sedimentation rate [ESR] and swollen joint count), which were also statistically significant. At baseline, patients with depression had significantly worse measures of inflammation and disease activity (C-reactive protein [CRP], ESR, and DAS28 [disease activity score including the assessment of 28 joints]) compared with those without depression. In contrast to depression, anxiety showed no relationship with ESR or CRP. These controlled observations are well aligned with the results of observational studies indicating that depression at baseline and, more particularly, persistent depression during treatment are associated with higher levels of disease activity at all times and negatively affect the rates of remission and low disease activity achieved using anti-tumor necrosis factor (TNF) therapy $[11,12]$. Therefore, rec- 
ognition and appropriate management of depression could improve the effectiveness of anti-TNF therapy. These psychological influences on response to treatment are especially relevant when adopting a holistic approach to the assessment of response to therapy by incorporating relevant patient-reported outcomes (PROs), such as quality of life and fatigue, alongside depression and anxiety [10]. We could not find any studies addressing the potential influence of psychological domains on response to medication in controlled circumstances.

\section{B. Disease Activity in the Clinical Setting and Associated Psy- chological Factors: Stress and Personality}

Although many patients with RA attribute their disease flares to psychological stress, research results are not conclusive [13]. Data indicate that enduring minor and interpersonal stressors can be related to concurrent or subsequent increases in disease activity [1416]. The study by Zautra is especially interesting, the disease activity increases in association with stress, and concurrent depression was mirrored by higher levels of circulating interleukin (IL) 6. Another study revealed a significant relationship between minor stressful events and disease activity [14]. Such interactions have been questioned by studies with negative results $[13,15,17]$. To date, studies on the relationship between personality traits, disease activity, and response to treatment are scarce and inconclusive [18].

A prospective study of patients with RA showed neuroticism to be a strong determinant of persistent low mood [19]. In their crosssectional study, Persson et al. (2002) found data to suggest that neuroticism is strongly associated with self-rated symptoms and well-being in RA [20]. Conversely, disease activity can influence the expression of personality traits: Hyphantis et al. (2006) found that during exacerbations of disease activity in early RA patients, personality profiling revealed characteristics of a borderline personality disorder [21]. The design of the study did not allow conclusions to be drawn regarding the nature and direction of causal relationships. Coping strategies are decisive modulators of the impact of disease on a patient's function and quality of life.

A recent review addressing the longitudinal association between coping and psychological distress in RA found evidence that maladaptive cognitive coping styles and patterns such as pessimism, catastrophizing, and cognitive distortions are associated with increased levels of psychological distress [22]. In osteoarthritis, catastrophizing is a determinant of pain, psychological disability, and physical disability [23], and increases in psychological distress have been observed to predict increases in osteoarthritis pain [24]. Somatization, the interpretation of innocuous bodily sensations as symptoms of disease, has been shown to exert a strong influence on health-related quality of life in RA, even after controlling for pain. In fact, the number of physical symptoms is affected by concurrent anxiety and depression, neuroticism, and negative affect at least as much as by objective measures of disease activity and cumulative joint damage [21]. Psychological aspects are obviously pivotal when considering lifestyle factors associated with disease activity and response to treatment in RA.

There is strong evidence to support the concept that a comprehensive treatment strategy for RA should include correction of excessive body weight and cessation of smoking. Both of these conditions are associated with severity of RA and reduce the efficacy of anti- TNF agents $[25,26]$. However, moderate alcohol consumption may decrease the severity and progression of RA, possibly by reducing levels of some inflammatory mediators [27- 29]. Excessive drinking will certainly increase the risk of liver toxicity for a variety of drugs, including MTX. Aerobic and strengthening exercises have been shown to provide significant improvements in the physical and psychological status of RA patients, including reduction in pain and fatigue and increased sense of well-being [30-32]. Obesity, smoking, and lack of exercise have all been related to higher levels of stress. However, it is not clear whether stress plays a role in mediat- ing their effect on disease activity and response to treatment. In any case, health behaviors and their modulation have a considerable impact on disease management. During the last decade, selfefficacy has arisen as one of the most important psychosocial variables when considering pain and disability in people with RA [33, 34]. Self-efficacy is the belief that one is capable of performing competently in specific situations.

RA patients who report higher levels of self-efficacy experience less pain, physical disability, fatigue, and negative mood $[35,36]$.

A study of 75 women with RA using questionnaires and a semistructured interview found that the group of patients who could better control the symptoms of RA described significantly lower levels of depression, pain, and physical disability [37].

Increases in self-efficacy that arise over the course of training in self-management or pain coping skills significantly predicted enhancements in RA pain, health status, and depression [38].

\section{C. Psychological Factors Influencing the Effectiveness of Therapy}

Long-term persistence and effectiveness of treatment in clinical practice is affected by factors that are often ignored in short-term clinical trials, namely, adherence, co-medication, and late adverse events. Observational studies are best suited to address these aspects and take into account a diversity of relevant outcomes not considered in short-term trials. Depression has been consistently associated with worse disease outcomes in patients with RA, including pain, tender joints, poor adherence to medication, increased healthcare service utilization, disability, and higher rates of early retirement $[2,5,39-42]$. Conversely, several studies have demonstrated that functional disability and loss of valued activities, such as employment, are associated with an increased risk of depression $[39,42,43]$. In addition, depression has been identified as an independent risk factor for cardiovascular disease, myocardial infarction, suicide, and all-cause mortality in patients with RA [44, 45]. The literature contains few references to the influence of psychological factors on the results of surgical management. A recent systematic review of factors involved in the perioperative management of major lower limb arthroplasty found that RA patients with clinical depression do not improve to the same extent as those without [46].

\section{POTENTIAL MECHANISMS INVOLVED IN FACTORS AFFECTING RESPONSE TO TREATMENT}

\section{A. Interactions between Psychological Domains and Biological Mechanisms of RA}

It has been repeatedly demonstrated that then immune system plays a pivotal role in the biology of a large array of psychiatric disorders, including not only major depression but also schizophrenia and autism [47-49]. Such observations support the possibility that the immune system plays a key pathophysiological role in the concomitant development and progression of psychopathology and autoimmune disorders. Depression and depressed mood are associated with a proinflammatory cytokine spectrum, as measured in peripheral blood. A recent meta-analysis confirmed that patients with depression have significantly higher levels of circulating TNFalpha and IL-6 than nondepressed age-matched controls. No significant differences were found for IL- $1 \beta$, IL-2, IL-4, IL-8, IL-10, or interferon [IFN] $\gamma[50]$. CRP also seems to be increased in depression [51, 52]. Moreover, it has been demonstrated that persistence of immune activation after treatment of major depression is a risk factor for relapse during the following months [53, 54]. There is abundant circumstantial evidence to support these findings. Depression has been shown to occur with remarkable frequency after immune challenges such as vaccination [55], administration of endotoxin [56], and anti-IFN- $\gamma$ therapy [57]. Conversely, there is evidence that anti-inflammatory therapies can relieve depressive symptoms in the absence of somatic disease [48, 58, 59]. Antide- 
pressive drugs have immunomodulatory effects. Despite conflicting results, their effect seems to be predominantly immunosuppressive, namely, a shift from $\mathrm{TH} 2$ to $\mathrm{TH} 1$ cytokine response patterns and decrease in levels of TNF-alpha, IL-1, and IL-6 while maintaining or increasing levels of anti-inflammatory cytokines such as IL-4 and IL-10 [60, 61]. Sertraline, a selective serotonin reuptake inhibitor (SSRI), was recently shown to decrease adjuvant-induced arthritis in rats as potently as MTX. This effect was associated with a significant increase in levels of the anti-inflammatory cytokine IL10, a decrease in TNF-alpha levels, and a decrease in cyclooxygenase-2 production [62]. Similarly, the SSRI fluoxetine has been shown to promote remission in an experimental model of autoimmune encephalomyelitis [63]. Individual case reports suggesting similarly remarkable effects of antidepressants in RA do not provide proof, but may boost our interest in researching this field [64].

In summary, depression is associated with a proinflammatory cytokine environment in the absence of any overt inflammatory condition and can be induced by immune challenges. Immunomodulators can influence the risk and expression of various psychological conditions and states. Immune mediators and autoimmune conditions can be modulated by psychoactive drugs. Such observations offer a myriad of possible bidirectional interactions between mood disorder and RA. Increased activity of RA when associated with depression and stress may be conceived as a simple reflection of the coexistence of 2 inflammatory conditions. The increased resistance to therapy in these circumstances may be related to the additional load of inflammatory mediators. Conversely, the increased prevalence of depression in RA and its amelioration with anti-TNF therapy may simply reflect the ability of the proinflammatory cytokines IL-6 and TNF-alpha to induce depression and sickness [51, 65]. Relief from depression when RA is in remission may be a direct effect of therapy on the biology of depression, at least as much as an indirect effect through improvement in the symptoms of RA and its impact on the patient's ability to enjoy life. In psoriasis, a randomized controlled trial of etanercept found that patients receiving anti-TNF-alpha drugs gained significant relief from depressive symptoms independently of improvement in disease activity, thus indicating a possible direct influence of TNF-alpha on depression [66]. It has been proposed that blockade of proinflammatory cytokines with biologics could represent a new approach to treating depression [67] that could also prove to be useful in inflammatory conditions such as RA. The neuroendocrine biology of RA provides several potential avenues for bidirectional psychological interactions. Similarly to immune challenge, acute psychological stress is associated with overactivation of the hypothalamic-pituitaryadrenal (HPA) axis, resulting in increased levels of circulating cortisol and activation of the autonomic nervous system. Cortisol suppresses inflammation through an array of mechanisms, including inhibition of the production of proinflammatory cytokines. These findings suggest that stressful circumstances would decrease inflammatory responses and ameliorate inflammatory conditions [68, 69]. However, chronic stress has a different biology: under persistent activation, the HPA axis eventually reduces the production of glucocorticoids, and persistent stress results in significant downregulation of the expression of glucocorticoid receptors. The same finding is observed in chronic persistent systemic inflammation. Chronic stress actually results in diminished levels of circulating glucocorticoids relative to levels that would have been adequate given the intensity of concomitant inflammation or psychological distress. These relatively low levels of circulating glucocorticoids act upon desensitized target cells [70, 71] and thus favor the increase in proinflammatory cytokine level and foster chronic inflammation. This paradoxical inhibition of glucocorticoid production in chronic stress and/or inflammation occurs mainly at the level of the adrenal response to adrenocorticotropic hormone. The production of corticotropin-release hormone $(\mathrm{CRH})$, induced by both psychological stress and proinflammatory cytokines (IL-6, TNF), remains elevated in chronic distress. Increased CRH levels contrib- ute directly to depression through special type II CRH receptors in the central nervous system $[71,72]$. Antidepressants also influence these mechanisms, for example, by increasing glucocorticoid receptor expression and function $[73,74]$. Studies on depressed patients found that the long-term effectiveness of antidepressant therapy depends on the correction of HPA axis hyperactivity $[75,76]$. Depression is also associated with low levels of melatonin in plasma and urine and alteration of circadian rhythms in RA patients. Melatonin and sleep have complex interactions with the immune system.

Humoral and cellular immunity are significantly influenced by melatonin through specific receptors, selective melatonin receptor MT1/MT2, and high-affinity nuclear receptors, which are found on leukocytes.

Melatonin inhibits translocation of NF- $\mathrm{kB}$ to the nucleus, thus reducing the production of proinflammatory cytokines such as IL-6 and TNF-alpha. However in most circumstances, this hormone seems to have a predominantly anti-adrenocortical and anti-stress action.

Antidepressives have shown to raise melatonin levels in depressed patients and to promote the restoration of biological rhythms [61]. While these interactions are incompletely understood at present, they do have potential in this field. The evidence briefly summarized above demonstrates that there is an overlap between the biological mechanisms underlying conditions classically considered diverse and independent, namely, autoimmune and other inflammatory diseases on the one hand and psychological conditions and traits on the other. This overlap provides potentially ample biological bidirectional communications and effects between these mechanisms.

\section{B. Psychological Dimensions Associated with Patient- Reported Outcomes and the Impact of Disease on Patients'} Lives

PROs are becoming increasingly relevant as measures of disease activity and response to therapy [77]. Given that these measures are more prone to emotional influence than the DAS28, the scientific community questions their validity and reproducibility. However, such criticism must be reconsidered if we recognize that they convey dimensions of disease and illness that are indispensible if we are to grasp the full impact on patients, in other words, the true importance of disease. Arthritis has intrinsically subjective dimensions, including pain, fatigue, depression, and anxiety, and these dimensions are as representative of disease burden as the number of swollen joints.

The RA Impact of Disease (RAID) score conveys patients' views on the impact of RA [78]. The more than 500 patients who were involved in the development of the RAID score identified 7 major domains as representing the overall burden of the disease: pain $(21 \%)$, functional disability $(16 \%)$, fatigue $(15 \%)$, emotional well-being $(12 \%)$, sleep disturbance $(12 \%)$, coping $(12 \%)$, and physical well-being (12\%) [79]. This study shows that patients consider emotions an integral part of their disease. Therefore, depression, anxiety, and other psychological dimensions such as helplessness, fear, and invalidation should not be seen as extrinsic factors undermining the reliability of the "true measures of disease activity", but as valid "additional measures of disease". We will fail to grasp the disease completely if we insist on keeping emotions and other subjective dimensions out of the equation. Below, we discuss each of the domains elected by patients to describe the impact of RA (RAID score) and explore their psychological dimensions.

Pain

A cross-sectional study showed strong associations between the severity of pain, sleep disturbances, and depression [80]. Given the biological pathways revised above, it is conceivable that these influences might be mediated by increased inflammation. However, 
Kojima et al. (2009) observed that severity of depression is positively associated with pain in patients with RA independently of the intensity of inflammation as measured by other parameters [81]. Depression, anxiety, and chronic stress have been shown to decrease the pain threshold and increase sensitivity to pain of different origins in humans and experimental pain in animals: pressure pain, thermal pain, visceral pain, formalin-induced hyperalgesia, and responsiveness to repetitive noxious mechanical stimuli (wind-up) [82-84]. It is difficult to ascertain the effect of emotions on disease activity and pain threshold in human disease, as one emotion tends to affect another. However, it seems reasonable to conceive that both the disease process and pain are affected by emotions.

\section{Functional Disability}

Studies indicated that the Health Assessment Questionnaire score, the most frequently used measure of physical disability in $\mathrm{RA}$, is associated with depression [85] and pain [2]. It has also been suggested that loss of valued activities caused by long-term disability and joint damage leads to depression [86]. Fatigue and pain also increase physical disability [87].

\section{Fatigue}

Although fatigue is a likely consequence of the disease process in RA [89], previous reports have shown that it is associated with pain and depression $[90,91]$, more strongly so than with other parameters of disease activity [87]. Psychosocial factors including health beliefs, perception of illness, and poor social support may influence the fatigue associated with RA [36, 92].

\section{Emotional Well-being}

Patients consider emotions an important outcome of their disease [79]. Studies have shown that quality of life is significantly lower in patients with RA than in patients with other inflammatory conditions, because their depression or anxiety scores are higher $[93,94]$

Kojima et al. (2009) suggested that disease activity evaluated by routine objective clinical examinations does not mirror the physical and mental quality of life of RA patients [81]. Clinicians should assess the psychosocial status, as well as their subjective disease status, in order to improve quality of life of RA patients [85]. This observation is coherent with the findings of Persson et al, who suggested that psychological factors performed better than disease activity as predictors of well-being among RA patients [95]. Interestingly, a subanalysis of the COMET study involving active early RA patients demonstrated that clinical remission with drug treatment is associated with improvement of PROs such as depression and anxiety [10]. In summary, it seems reasonable to expect that the abrogation of the inflammatory process in RA will assist in controlling depression and anxiety in some but not all patients. Thus, comorbid depression and anxiety must be evaluated and taken into account when trying to assess and control the impact of RA on patients' lives [94].

\section{Sleep Disturbances}

Sleep disturbances have been associated with higher levels of pain, fatigue, and depression in patients with RA [96-98]. In a longitudinal analysis, Nicassio et al. (1992) found that pain can exacerbate sleep disturbances in RA patients, and that both factors can contribute to depression over time [99]. Additionally, sleep deprivation can cause musculoskeletal pain, even in healthy people, and it adds to fatigue and to decreased overall sense of well-being. Moreover, sleep deprivation has been shown to result in higher circulating levels of CRP, prostaglandin E2, and IL-6 [100].

\section{Coping Styles and Strategies}

The stress-coping model has been widely used to understand psychological adjustment to RA. Coping refers to the cognitive and behavioral efforts that people make to manage situations that are considered as stressful [101]. Numerous coping strategies have been differentiated (eg, problem- focused vs emotion-focused, ac- tive vs passive, and engagement vs disengagement) and categorized employing a hierarchical taxonomy of coping [102]. RA patients adopting passive coping strategies (especially avoidance, helplessness, and wishful thinking) tend to have more pain and higher degrees of disability $[22,103,104]$.

Cross-sectional studies consistently showed that avoidance oriented coping is linked to poor psychological well-being [105, 106]. Catastrophizing has been found to be especially harmful for daily functioning in patients with RA [107] and in patients with other rheumatic conditions such as low back pain, fibromyalgia, and osteoarthritis [108]. In this regard, people with RA may be hypersensitive to certain stressors and/or generate a more marked response to stress [109]. While the use of active coping strategies is usually found to be helpful, in instances where it is not possible to change the stressor, continued attempts at problem solving may result in heightened distress. It has been suggested that coping flexibility, ie, the use of a variety of coping strategies in different situations, may be the most beneficial factor for adjustment to RA, particularly because of the fluctuating and often unpredictable course of the disease [110]. The concepts of "locus of control" and "self-efficacy" also deserve consideration in this context. Patients with an internal locus of control are more likely to take control of their health, feel capable of developing strategies to deal with pain (self-efficacy), and report lower pain intensity [111]. On the other hand, those with an external locus of control have low confidence in their ability to manage and reduce their pain and may thus avoid intensifying their activity level [112].

In a cross-sectional study of 70 RA patients, it was suggested that patients with both a high internal locus of control and high selfefficacy described better health status than patients with a low internal locus of control and low self- efficacy [113]. Moreover, higher levels of self-efficacy for physical activity increase the probability that patients with RA will achieve their physical activity goals [114]. Finally, increasing self-efficacy beliefs is a common ingredient of cognitive-behavioral therapy and has proven effective [38]. Spiritual and religious resources are relatively recent areas of study in pain research. Both can have a substantial impact on the patient's perception of pain, suffering, and disease burden. A multicenter cross-sectional study of 580 patients [115] showed significant associations between spiritual resources, positive appraisal, and internal adaptive coping strategies, suggesting that spiritual resources go beyond fatalistic acceptance and actually operate as an active coping strategy.

In a meta-synthesis analyzing the status of spiritual well-being, the investigators identified four consistent situations related to RA patients' spiritual well-being: living with the disease, reclaiming control, reframing the situation, and bolstering courage [116]. The authors highlight that spiritual well-being should be incorporated into quality of life evaluations of RA patients and may afford an evaluation tool able to explain the variability of the effectiveness of various interventions. In a recent case-control study [117], the authors found that 637 patients with RA and 496 healthy controls score differently on 8 specific domains of the Trait Emotional Intelligence Questionnaire. The RA group scored higher on relationships and empathy and lower on stress management, emotion management, adaptability, assertiveness, impulsiveness, and self-esteem $(\mathrm{p}<0.0025)$.

In summary, coping strategies play a key role in determining the impact of similar disease conditions on suffering, pain, disability, and enjoyment of life. Physicians frequently recognize this in their practice, although a structured approach to the assessment and training of coping strategies is usually absent.

\section{C. Psychological Influences on Measures of Disease Activity and Response to Therapy}

Placebo and nocebo effects - Psychological influences on pain, suffering and modulation by medical treatment. 
In randomized clinical trials of DMARDs, $15-35 \%$ of patients with RA respond to placebo according to the American College of Rheumatology (ACR) 20\% criteria. Improvements are usually evident within 1-3 months and may persist for as long as 12 months $[118,119]$. A meta-analysis of placebo response in osteoarthritis [120] confirmed an appreciable effect size of placebo in the treatment of this condition, particularly for subjective outcomes (pain, stiffness, self-reported function) and the doctor's global assessment. Placebo seems to have no effect on more objective outcomes, such as range of motion. The contextual features underlying the placebo effect have been closely studied in pain and may reflect nonspecific aspects of the patient-physician relationship, including attention, compassionate care, modulation of expectations, anxiety, and selfawareness [121]. Curiously, in a multicenter randomized controlled trial of a new agent for RA resistant to MTX, ACR2 0 response rates in both the placebo and active drug groups were higher among patients from Latin America and Eastern Europe than patients from the USA [122]. Some authors have hypothesized that patients with RA from economically disadvantaged countries with a lower socioeconomic status and lower educational level have a substantially poorer clinical status than those from developed countries, who have considerably greater capacity for improvement [123]. It could also be argued that the opportunity of receiving such new agents can be expected to have a much higher emotional bearing-and thus potential placebo effect - in developing countries. The determinants of the magnitude of the placebo effect on osteoarthritis pain were identified in a meta-analysis of randomized controlled trials: the pain-relieving effect of placebo was greater when the active treatment effect, the baseline level of pain, and the sample size were higher and when placebo was administered by injection [120]. Interestingly, the placebo effect increases as the effect size of treatment increases. This finding suggests that a higher level of expectation of benefit by participants (and assessors), as reflected in the placebo effect, is also part of the effect of the experimental medication $[120,124]$. In any case, the data from this meta-analysis suggest that placebo is truly more effective as an analgesic over nontreatment (observation only). The superior placebo effect in this meta-analysis was observed in studies with larger samples, suggesting that in the presence of superior placebo effects, larger samples are needed to show significant differences and positive studies have a higher chance of publication than negative ones (publication bias) [120]. In fact, numerous neurofunctional studies have now established beyond reasonable doubt that the effect of placebo on neuronal activity at CNS sites associated with modulation of physical pain is similar to that of analgesics $[125,126]$. This means that placebo significantly changes the pain experience and, therefore, the perception of painful disease. A similar yet contrary effect is observed with nocebo, ie, the detrimental effect induced by negative cognitions [127]. Although the scientific method has endeavored to separate placebo effect from active medication effects, we must recognize that, when it comes to pain, placebo effects are at least as real as those achieved with active medication. The efficacy of "proven effective" medication also incorporates the placebo effect and would certainly be diminished by efforts to exclude any influence of context on the effect of medication by diminishing the placebo effect. Systematic reviews show that the doctor-patient relationship has an important therapeutic effect, irrespective of prescribed treatment.

Physicians who assume a warm, friendly, and calming style are more effective than those who maintain consultations formal and do not offer encouragement [128].

\section{The DAS Score and its Components}

Results from the COMET study show that the self-assessed, subjective parameters of disease activity (ie, tender joint count and global health reports) had a stronger association with depression than the objective parameters (swollen joint count and ESR), although the correlation was statistically significant in both cases
[10]. However, one should refrain from assuming that depressed patients exaggerate in their assessment of tender joints or global health. As outlined above, there is abundant reason to assume that depression may actually change the disease and its impact on the patient. Cross-sectional studies provide conflicting results, with most describing an association between depressed mood and objective measures of disease activity, such as CRP and ESR $[6,11,81$, 129, 130]; however, others do not find such associations [131, 132]. Some authors have found that anxiety does not correlate with ESR or CRP in RA patients $[10,133]$, whereas others show that anxiety and disease activity were positively associated when measured simultaneously and 6 months apart [6]. While the latter study found some support for the condition that a higher level of disease activity is a risk factor for increased psychological distress, the findings did not confirm the hypothesis that psychological distress is a risk factor for future exacerbation of disease activity.

Furthermore, in patients with RA and concomitant/secondary fibromyalgia, DAS28 has been reported to overestimate disease activity [124, 125], possibly because of application of the visual analog scale for general health and tender joint count, which focus on the more subjective components of DAS28 [48]. These authors suggested that in order to reliably estimate an individual's disease activity, the individual components of DAS28 should also be examined, and that if the 2 measures listed above are high relative to ESR and swollen joint count, tender joints should be assessed. In the study by Mattey et al. (2010), discontinuation of anti-TNF was associated with depression, anxiety, and disease activity at baseline, suggesting that disease activity and psychological distress also independently predict the effect of biologics [12].

\section{D. Influence of Psychological Factors on Long-Term Effec- tiveness of Treatment}

Many factors can negatively influence the long-term effectiveness of drugs that have been shown to be efficacious in shorter clinical trials. Most of these relate to cognitions and behavior, thus entering the realm of psychological domains.

\section{Adherence, Beliefs, Expectations, and Communication}

Reported adherence rates in RA vary from $30 \%$ to $93 \%$ [34, 134]. This will forcibly have a high impact on the results of treatment in clinical practice. Expectations regarding the effects and side effects of therapy are essential for successful adherence [135]. Female gender, middle age, busy lifestyle, cognitive deficits, depression, higher income, and employment status have all been associated with nonadherence [136, 137]. Garcia- Gonzalez et al. (2008) found that Hispanic and African American patients have significantly lower levels of adherence to medication than Caucasian patients [138]. The authors attributed these findings to a stronger feeling of depression and perceptions of medication as harmful in ethnic minorities. Similar findings have been reported by Kumar et al. (2008), who compared South Asian patients with Caucasian British patients [139]. Health expectations and patient attitude also influence the kinds of treatments that can be realistically offered. Psychological aspects of the prescribing physician and divergence between patients and physicians also play a role. For example, patients with early RA were less reluctant to accept combination therapy with conventional DMARDs and biologics than rheumatologists [133-136], and a study analyzing the European League Against Rheumatism Recommendations on the management of glucocorticoid therapy demonstrated important discrepancies between patients' and rheumatologists' perspectives that might negatively affect the implementation of the recommendations [137]. Such beliefs and divergence need to be addressed, as they may unduly interfere with the physician's selection of therapy and with the patient's commitment to the strategy. Communicating, discussing the goals and alternatives of the treatment with the patients, and making joint decisions seem to be essential for achieving optimal adherence $[48,140]$. 


\section{Social Aspects of Response to Therapy}

Psychological aspects can both influence and be influenced by social context. Examples include the presence or absence of encouragement by family, social support, and invalidation, as well as aspects related to cultural/geographical background and gender. RA is especially challenging for spouses or partners.

Both partners and patients may lack the confidence to communicate effectively about fatigue and pain and resist discussing painrelated topics with each other.

Partners who resist discussing pain (eg, overprotective partners) reveal higher levels of caregiver tension, and their patient partners described much higher levels of psychological disability and pain catastrophizing [141]. Furthermore, depressed partners may experience coping problems with a chronic illness. High levels of spousal depressive symptoms, for example, have been shown to predict worsening of disability and disease activity over a 1-year period $[23,142]$. Well-intentioned people close to the patient can offer unhealthy social support. Spouses who, for instance, in an assertive and lecturing way "know" what is best for the patient can impede the patient's feeling of independence and self-control [143].

Lack of reciprocity in a relationship, ie, obtaining more support than one provides (over- benefit) and providing more support than one receives (under-benefit) is psychologically distressing [144]. Social support beyond the immediate family is critical in the adjustment to RA.

Obtaining support from others generally results in mental benefit and physical health and may dampen the destructive impact of disease stressors or external stressors, as shown in patients with fibromyalgia [145] and in patients with RA [146]. Patients with RA may benefit from emotional social, informational, behavioral, or tangible forms of social support.

High levels of social support, such as (the perception of) being cared for and having assistance available from family and friends, may protect against anxiety [133]. Workplace support can help individuals to adjust better to painful disorders. Li (2006) found that patients who reported low workplace support were much more likely to develop depressive symptoms within 18 months [42]. Few studies have investigated the interaction between cultural/geographical background and response to treatment in RA. Recent studies found racial/ethnic differences in PROs of function and global disease assessments [147, 148]. These discrepancies could result from differences in interpretation and completion of outcome instruments, which, although often transculturally validated, may not guarantee transcultural comparability of results.

\section{INTERVENTIONS USED TO BENEFIT THE PATIENT \\ Treating Depression/Anxiety}

Given its impact on the patient's quality of life, clinically overt depression associated with RA should be treated as a separate entity, as long as there are no contraindications. The evidence that concomitant depression hinders the efficacy of DMARDs further supports the need to systematically look for and treat depression in RA. This assertion holds, even if effective treatment with biological agents such as infliximab, etanercept, or adalimumab has been shown to reduce the prevalence of depression in RA patients. Yet, it remains unclear whether antidepressants and psychological therapies confer their expected benefits in patients with RA who are diagnosed with an anxiety disorder or depression according to established criteria [4]. The possibility of using antidepressants or psychological interventions for depression with the intention of improving RA (especially, but not only, in the presence of concomitant depression) is appealing and biologically plausible. Unfortunately, this possibility has never been formally tested. Antidepressants have a beneficial effect on pain and reduce disease activity in patients with RA [149]. However, the impact of antidepressants or cognitive behavioral therapy on broad healthcare outcomes such as disease activity, disability, and health status has not been established for persons with RA [150]. At present we can only speculate that, since treatment with antidepressants is associated with reduced levels of proinflammatory cytokines, these drugs hold promise as adjuvant therapies for RA, especially in patients with depression.

Psychological interventions have also been expanded for patients with rheumatic diseases and relatively high scores for anxiety or depressive symptoms but who do not fulfill the established diagnostic criteria for these conditions. Evidence showed that over and above standard care, psychological interventions can successfully improve physical and psychological performance and reduce longterm consumption of medical resources [151-154].

A meta-analysis of randomized controlled trials in RA demonstrated that cognitive- behavioral therapies are effective at improving pain, disability, coping, self-efficacy, and psychological distress, with small to moderate effect sizes [151].

\section{Can we Use the Placebo Effect to Benefit the Patient?}

One review highlighted the placebo effect and some determinants of "placebo responses" [155]. Treatments that are perceived as being more powerful tend to have a stronger placebo effect than those that are perceived to be less so.

Furthermore, the same substance has been found to be more powerful when it is branded than when it is not. Greater placebo effects have been reported with injections than with oral medication in many conditions. Moreover, adherence to what the patient believes to be a beneficial treatment is itself beneficial to health outcomes $[156,157]$. The environment in which the patient receives treatment may also modify outcome. Patient-physician communication plays a key role in the placebo response. A positive consultation is one where the physician gives a confident diagnosis, is optimistic that the treatment will help and be safe, wants to monitor the patient's progress, and reassures the patient that things will improve soon. Addressing the patients' concerns and misinterpretations may reduce the nocebo effects of fear and diminish the risk of intolerance and early treatment withdrawal.

Although there is no general opinion on the role of placebo and how to optimize it, practicing clinicians know that they would pay a disservice to their patients if they disregarded it and, even more, if they tried to avoid it. Physicians recognize hope as an essential part of what they have to offer their patients.

\section{Patient Education and Self-Management}

Encouraging and supporting people with RA to take more control of their illness by engaging in self-management has increasingly become a focus in many health services. One particular push for this approach is the increasing recognition that with an ageing population and the consequent increase in the frequency of chronic disease, health services will have to change their model for treating chronic disease [158]. The primary objectives of patient education are to present the rationale for the treatment in an understandable way, to elicit active collaboration between patients (and their caregivers) and the clinician, and to help patients gain confidence in their ability to adapt to the consequences of the disease. It is particularly important to encourage RA patients and spouses to adopt the belief that they can learn the skills necessary to cope better with the patients' illness-related problems and overcome helplessness. Self-management is defined as the extent to which the patient regulates and is responsible for his/her own treatment and care. Selfmanagement and medical care are more complementary than incompatible, and both patients and professionals depend on each other to control disease activity and pain and prevent (progression of) joint destruction and disability. This dependence includes the management of daily activities and medication. 


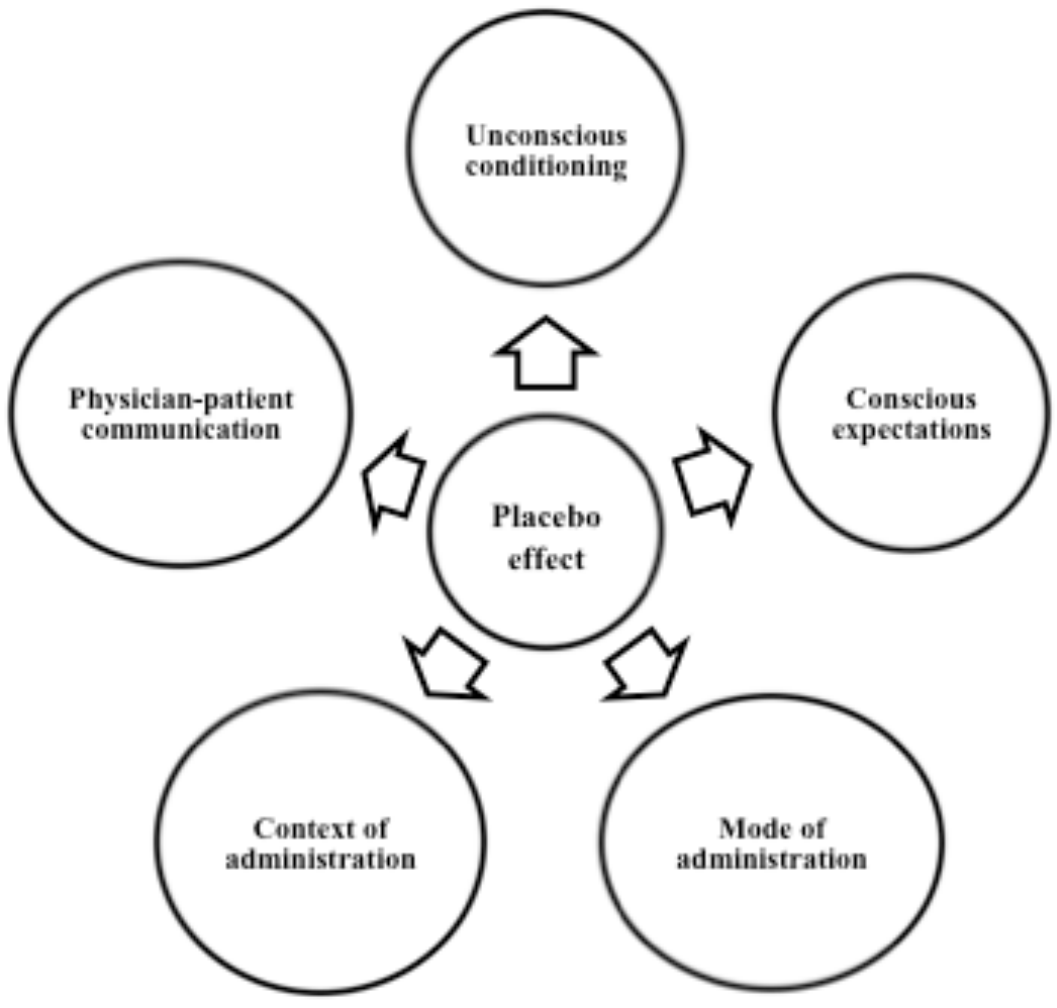

Fig. (1). The determinants of "placebo responses". (Doherty M. and Dieppe P., 2009).

Enabling self-management for people with long-term conditions should be part of rheumatology practice. Many rheumatology teams provide general education in self-management. However, many clinicians are uncertain how to help.

The most effective means of providing a self-management program is through individual cognitive behavioral therapy, which uses a variety of techniques, including cognitive restructuring of dysfunctional beliefs and "worry" thoughts, relaxation training, positive self-talk, and exposure to anxious situations, thoughts, and worries.

In cognitive behavioral therapy, the essential self-management strategies of problem solving and goal setting improve self-efficacy and confidence that one can do something to make a difference. A systematic review of general self-management programs in rheumatic diseases suggested incorporation of the cognitive behavioral therapy and self-efficacy principles [159]. Data suggest that in patients with RA, cognitive behavioral therapy targeting illness cognitions results in better outcomes [160]. However, any psychological intervention should only be provided after a thorough psychiatric evaluation. Self-determination theory is popular in the field of selfmanagement [161]. The basic premise of this theory is that motivation is determined by 3 basic needs: autonomy, competence, and social relatedness. Of these, autonomy takes a central position: if a behavior is autonomous, it is voluntary, originating from one's own values, and self- determined. A patient will be more inclined to conduct and persist in autonomous behavior than in externally directed behavior. Competence includes the need to feel that one is really able to achieve something and is related to the construct of self-efficacy. The third basic need, social relatedness, is the extent to which one finds support in one's environment, including one's coach or therapist. High levels of autonomy, competence, and social relatedness enhance self-management. Motivational interviewing is the primary tool for ensuring autonomous motivation [162]. Even in the absence of a formal program, research reveals that committed health professionals can play an important role in enhancing patients' well-being by promoting self-awareness, coping skills to deal with stress, sense of empowerment and confidence, and the ability to live with meaning and hope [163].

\section{Patient Education. Coping Skills}

To enhance physical and psychological functioning, cognitivebehavioral interventions generally try to modify coping strategies by addressing dysfunctional thoughts and pain- related behaviors with the aim of improving long-term psychological and physical outcomes. The purpose of the initial component of training in coping skills is to help patients and spouses involve actively in the process of learning new strategies (eg, relaxation, and pacing of activity and daily resting periods) and to replace unhelpful cognitions with helpful ones.

This phase enhances self-efficacy, reduces perceptions of helplessness, and helps patients to better cope with the disease-related problems. Patients and their partners are stimulated to practice and integrate these new cognitive and behavioral coping strategies and to apply them efficiently at home and at work. In the relapse phase, patients are stimulated to continue use of their coping strategies and treatment gains.

Most well-designed studies on psychosocial interventions in RA have highlighted training in relaxation and coping strategies, including stress management, avoidance of catastrophizing, and positive reinforcement of healthy behavior in order to improve perceptions of control and self-efficacy. These interventions have produced statistically significant improvements in pain scores, exhibitions of pain behavior, reductions in affected joint counts and improvements in patients' scores of helplessness, self-efficacy, disability, and distress $[151,152,164]$. Typically, relapses occur when the intensity of symptoms begins to increase, since patients' perception of symptom control is diminished, and when patients experience psychological distress of any origin [165]. 


\section{Patient Education. Therapeutic Contract: Promoting Adher-} ence

The factors most associated with increased adherence to medication in RA are higher levels of self-efficacy and social support $[166,167]$. The interested practitioner should promote these factors and investigate and correct (where possible) problems with adherence. The cause of such behavior has been addressed by the selfexpectation efficacy theory [168]: adherence is influenced by the balance between patients' beliefs about the need for treatment and their concerns about the risks. Communication between physician and patient is crucial to adherence. Muller et al. (2012) found that patients who were satisfied with their physicians had significantly higher levels of adherence than those who were not [48]. Other studies have found that improved patient knowledge about the disease and the medication and a higher frequency of visits to the physician are correlated with better adherence $[169,170]$. In addition, more frequent monitoring will increase the chance of early identification and control of disease flares, adverse effects, and substantial mood changes To promote adherence, practitioners require support and training in communicating the benefits and risks of therapies and in assessing and incorporating of patients' beliefs into the consultation process, while policymakers need to reduce barriers to access to treatment, such as drug costs where this is relevant [171].

\section{Working on the Social Environment}

Invalidation (lack of understanding and discounting by others) is a crucial social aspect of disease burden. It includes negative social responses (denying, lecturing, and overprotecting), as well as a lack of positive social responses (supporting and acknowledging), and may represent a significant problem for people with RA [143]. Invalidation may actually increase the risk of becoming depressed and physically impaired [172], thus highlighting the need to take invalidation into account in research and clinical settings [4]. Indeed, greater satisfaction with emotional support and social companionship are related to reduced distress in patients with RA [173].

\section{CONCLUSION}

This article reviews the potential psychological determinants, mechanisms, and interventions that may be involved in response to treatment in RA, including not only disease activity, but also the impact of the disease on the patient. The psychological consequences of RA are gaining importance, and PROs are increasingly taken into consideration. The psychological burden of RA on spouses, relatives, and caregivers is also attracting more attention. A true partnership with patients and their caregivers based on education, shared decision-making, and self-management is an indispensable tool for ensuring the success of therapy. In parallel, researchers and clinicians now realize that the psychological status of patients with RA, especially those with depression, must be taken into account in order to achieve the best possible results in a variety of relevant outcomes, from immune regulation to pain, disease activity, prevention of disability, and quality of life. The biological mechanisms underlying these factors, with emphasis on neuroendocrine immunology, are becoming increasingly clear, opening novel avenues for intervention (Fig. 2).

Access to psychological support tailored to the psychological needs of the individual patient is warranted for optimal outcome, as is conventional treatment. All RA patients should be evaluated for depression, and appropriate treatment with antidepressants or psychotherapy should be started when indicated. The potential benefits of antidepressive interventions for RA in the absence of depression have not been established. Such approaches will facilitate greater improvements in the psychological and physical status of people with RA, enabling them to live a more fulfilling and possibly also longer life.

\section{FUTURE RESEARCH}

Research is needed to clarify whether inclusion of PROs in current disease evaluations can lead to improved relevant outcomes for the patient by narrowing the gap between the patient and the physician's perspective. The sensitivity to change of many PROs

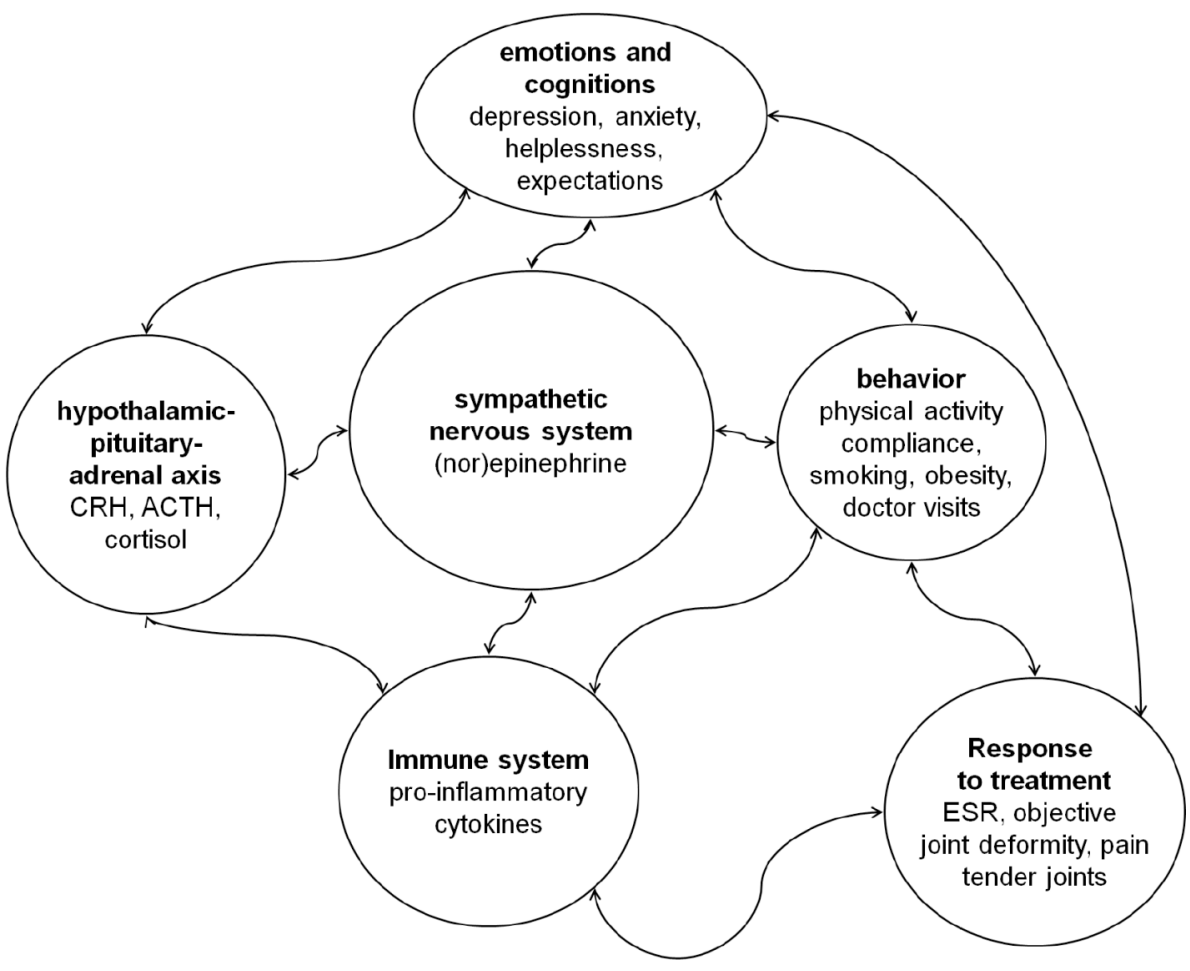

Fig. (2). Potential associations between psychological state and response to treatment in RA. In most cases, the root cause remains unclear, although it is most probably bidirectional and may change during different phases of the disease course. 
should be assessed (eg, RAID score). New PROs should be continuously developed to guarantee that truly relevant domains are covered in a cross-culturally valid way. Instruments such as the Personal Life Impact Measurement Scales seem especially promising $[174,175]$. Studies addressing the influence of psychological variables on response to medication in randomized controlled trials are urgently needed, as are new efforts and training to foster our understanding of coping strategies, by focusing on longitudinal and within- person research designs (eg, daily diary studies). Outcome criteria should be related to the autonomous needs and goals of each patient, namely, preserving autonomy, social relationships, and valued activities.

Available evidence indicates the need for a trial on the potential role of antidepressant medication in patients with RA. The indication is obvious in the presence of comorbid depression, as this directly impacts the patient's quality of life. However, the immunomodulatory effects of antidepressants and the presence of biological pathways that are common to depression and RA support the hypothesis that antidepressants may have positive effects on RA, even in the absence of depression. Basic and clinical research designed to understand the biological pathways involved in interactions between disease process and psychosocial domains will play a key role in opening new avenues of intervention.

\section{CONFLICT OF INTEREST}

The authors confirm that this article content has no conflict of interest.

\section{ACKNOWLEDGEMENTS}

Declared none.

\section{ABBREVIATIONS}

$\begin{array}{ll}\text { ACR } & =\text { American College of Rheumatology } \\ \text { CRH } & =\text { Corticotrophin-releasing hormone } \\ \text { CRP } & =\text { C-reactive protein } \\ \text { DAS28 } & =\text { Disease activity score including the assessment of } \\ \text { ESR } & =\text { Erythrocyte sedimentation rate } \\ \text { HPA } & =\text { Hypothalamic-pituitary-adrenal } \\ \text { HAQ } & =\text { Health assessment questionnaire } \\ \text { IL } & =\text { Interleukin } \\ \text { MTX } & =\text { Methotrexate } \\ \text { PLIMS } & =\text { Personal Life Impact Measurement Scales } \\ \text { PROs } & =\text { Patient-reported outcomes } \\ \text { RA } & =\text { Rheumatoid arthritis } \\ \text { RAID } & =\text { Rheumatoid Arthritis Impact of Disease } \\ \text { SSRI } & =\text { Selective serotonin reuptake inhibitor } \\ \text { TNF } & =\text { Tumor necrosis factor }\end{array}$

\section{REFERENCES}

[1] McWilliams LA, Clara IP, Murphy PD, Cox BJ, Sareen J. Associations between arthritis and a broad range of psychiatric disorders: findings from a nationally representative sample. J Pain, 2008; 9: $37-44$.

[2] Dickens C, McGowan L, Clark-Carter D, Creed F. Depression in rheumatoid arthritis: a systematic review of the literature with meta-analysis. Psychosom Med, 2002; 64: 52-60.

[3] Covic T, Tyson G, Spencer D, Howe G. Depression in rheumatoid arthritis patients: demographic, clinical, and psychological predictors. J Psychosom Res, 2006; 60: 469-76.

[4] Geenen R, Newman S, Bossema ER, Vriezekolk JE, Boelen PA. Psychological interventions for patients with rheumatic diseases and anxiety or depression. Best Pract Res Clin Rheumatol, 2012; 26: 305-19.
[24] Wise BL, Niu J, Zhang Y, Wang N, Jordan JM, Choy E, Hunter DJ. Psychological factors and their relation to osteoarthritis pain. Osteoarthritis Cartilage, 2010; 18: 883-7.

[25] Kim SC, Yelin E, Tonner C, Solomon DH. Changes in use of disease modifying anti-rheumatic drugs for rheumatoid Arthritis in the U.S. for the period 1983-2009. Arthritis Care Res (Hoboken), 2013.

Isik A, Koca SS, Ozturk A, Mermi O. Anxiety and depression in p

Overman CL, Bossema ER, van Middendorp H, Wijngaards-de Meij L, Verstappen SM, Bulder M, Jacobs JW, Bijlsma JW, Geenen R. The prospective association between psychological distress and disease activity in rheumatoid arthritis: a multilevel regression analysis. Ann Rheum Dis, 2012; 71: 192-7.

Wiltink J, Beutel ME, Till Y, Ojeda FM, Wild PS, Munzel T, Blankenberg S, Michal M. Prevalence of distress, comorbid condi2011; 130: 429-37. .

physiology and clinical implications. Curr Psychiatry Rep, 2008; 10: 258-64 Improvements in patient-reported outcomes, symptoms of depression and anxiety, and their association with clinical remission among patients with moderate-to-severe active early rheumatoid arthritis. Rheumatology (Oxford), 2011; 50: 401-9.

Hider SL, Tanveer W, Brownfield A, Mattey DL, Packham JC.

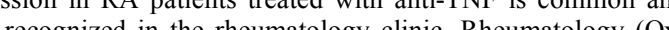
ford), 2009; 48: 1152-4.

Mattey DL, Dawes PT, Hassell AB, Brownfield A, Packham JC. Effect of psychological distress on continuation of anti-tumor necrosis factor therapy in patients with rheumatoid arthritis. J Rheumatol, 2010; 37: 2021-4 autonomic nervous system responsiveness in rheumatoid arthritis. Ann N Y Acad Sci, 2006; 1069: 77-97.

Potter PT, Zautra AJ. Stressful life events' effects on rheumatoid arthritis disease activity. J Consult Clin Psychol, 1997; 65: 319-23.

Affleck G, Urrows S, Tennen H, Higgins P, Pav D, Aloisi R. A tis. Aathway model of daily stressor effe

Zautra AJ, Yocum DC, Villanueva I, Smith B, Davis MC, Attrep J, Irwin M. Immune activation and depression in women with rheumatoid arthritis. J Rheumatol, 2004; 31: 457-63.

. Stress-vulnerability factors as long-term predictors of disease activ302 . neuroticism on chest pain symptoms and coronary artery disease. Am J Cardiol, 1987; 60: 20j-26j.

Affleck G, Urrows S, Tennen $\mathrm{H}$, Higgins P. Daily coping with pain from rheumatoid arthritis: patterns and correlates. Pain, 1992; 51: 221-9.

Persson LO, Sahlberg D. The influence of negative illness cognitions and neuroticism on subjective symptoms and mood in rheumatoid arthritis. Ann Rheum Dis, 2002; 61: 1000-6. traits in early rheumatoid arthritis: A preliminary survey. Rheumatol Int, 2006; 26: 828-36.

Vriezekolk JE, van Lankveld WG, Geenen R, van den Ende CH. Longitudinal association between coping and psychological distress in rheumatoid arthritis: a systematic review. Ann Rheum Dis, 2011; 70: $1243-50$.

Somers TJ, Keefe FJ, Pells JJ, Dixon KE, Waters SJ, Riordan PA, Blumenthal JA, McKee DC, LaCaille L, Tucker JM, Schmitt D, Caldwell DS, Kraus VB, Sims EL, Shelby RA, Rice JR. Pain catastrophizing and pain-related fear in osteoarthritis patients: relationships to pain and disability. J Pain Symptom Manage, 2009; 37: 
[26] Mattey DL, Brownfield A, Dawes PT. Relationship between packyear history of smoking and response to tumor necrosis factor antagonists in patients with rheumatoid arthritis. J Rheumatol, 2009; 36: 1180-7.

[27] Lu B, Solomon DH, Costenbader KH, Keenan BT, Chibnik LB, Karlson EW. Alcohol consumption and markers of inflammation in women with preclinical rheumatoid arthritis. Arthritis Rheum, 2010; 62: 3554-9

[28] Maxwell JR, Gowers IR, Moore DJ, Wilson AG. Alcohol consumption is inversely associated with risk and severity of rheumatoid arthritis. Rheumatology (Oxford), 2010; 49: 2140-6.

[29] Kallberg H, Jacobsen S, Bengtsson C, Pedersen M, Padyukov L, Garred P, Frisch M, Karlson EW, Klareskog L, Alfredsson L. Alcohol consumption is associated with decreased risk of rheumatoid arthritis: results from two Scandinavian case-control studies. Ann Rheum Dis, 2009; 68: 222-7.

[30] Van den Ende CH, Vliet Vlieland TP, Munneke M, Hazes JM. WITHDRAWN: Dynamic exercise therapy for treating rheumatoid arthritis. Cochrane Database Syst Rev, 2008: Cd000322.

[31] de Jong Z, Munneke M, Zwinderman AH, Kroon HM, Jansen A, Ronday KH, van Schaardenburg D, Dijkmans BA, Van den Ende $\mathrm{CH}$, Breedveld FC, Vliet Vlieland TP, Hazes JM. Is a long-term high-intensity exercise program effective and safe in patients with rheumatoid arthritis? Results of a randomized controlled trial. Arthritis Rheum, 2003; 48: 2415-24.

[32] Hurkmans E, van der Giesen FJ, Vliet Vlieland TP, Schoones J, Van den Ende EC. Dynamic exercise programs (aerobic capacity and/or muscle strength training) in patients with rheumatoid arthritis. Cochrane Database Syst Rev, 2009: Cd006853.

[33] Brekke M, Hjortdahl P, Kvien TK. Changes in self-efficacy and health status over 5 years: a longitudinal observational study of 306 patients with rheumatoid arthritis. Arthritis Rheum, 2003; 49: 3428 .

[34] Taal E, Rasker JJ, Seydel ER, Wiegman O. Health status, adherence with health recommendations, self-efficacy and social support in patients with rheumatoid arthritis. Patient Educ Couns, 1993; 20: 63-76.

[35] Barlow JH, Cullen LA, Rowe IF. Educational preferences, psychological well-being and self-efficacy among people with rheumatoid arthritis. Patient Educ Couns, 2002; 46: 11-9.

[36] Riemsma RP, Rasker JJ, Taal E, Griep EN, Wouters JM, Wiegman O. Fatigue in rheumatoid arthritis: the role of self-efficacy and problematic social support. Br J Rheumatol, 1998; 37: 1042-6.

[37] Groarke A, Curtis R, Coughlan R, Gsel A. The role of perceived and actual disease status in adjustment to rheumatoid arthritis. Rheumatology (Oxford), 2004; 43: 1142-9.

[38] Smarr KL, Parker JC, Wright GE, Stucky-Ropp RC, Buckelew SP, Hoffman RW, O'Sullivan FX, Hewett JE. The importance of enhancing self-efficacy in rheumatoid arthritis. Arthritis Care Res, 1997; 10: 18-26.

[39] Katz PP, Yelin EH. Prevalence and correlates of depressive symptoms among persons with rheumatoid arthritis. J Rheumatol, 1993; 20: 790-6.

[40] Berkanovic E, Hurwicz ML, Lachenbruch PA. Concordant and discrepant views of patients' physical functioning. Arthritis Care Res, 1995; 8: 94-101.

[41] Clemmey PA, Nicassio PM. Illness self-schemas in depressed and nondepressed rheumatoid arthritis patients. J Behav Med, 1997; 20: 273-90.

[42] Li X, Gignac MA, Anis AH. Workplace, psychosocial factors, and depressive symptoms among working people with arthritis: a longitudinal study. J Rheumatol, 2006; 33: 1849-55.

[43] Margaretten M, Barton J, Julian L, Katz P, Trupin L, Tonner C, Graf J, Imboden J, Yelin E. Socioeconomic determinants of disability and depression in patients with rheumatoid arthritis. Arthritis Care Res (Hoboken), 2011; 63: 240-6.

[44] Treharne GJ, Lyons AC, Kitas GD. Adherence to medication. N Engl J Med, 2005; 353: 1972-4; author reply 1972-4

[45] Scherrer JF, Virgo KS, Zeringue A, Bucholz KK, Jacob T, Johnson RG, True WR, Carney RM, Freedland KE, Xian H, Caplan L, McDonald J, Eisen SA. Depression increases risk of incident myocardial infarction among Veterans Administration patients with rheumatoid arthritis. Gen Hosp Psychiatry, 2009; 31: 353-9.

[46] Clement ND, Breusch SJ, Biant LC. Lower limb joint replacement in rheumatoid arthritis. J Orthop Surg Res, 2012; 7: 27.
[47] Gibney SM, Drexhage HA. Evidence for a Dysregulated Immune System in the Etiology of Psychiatric Disorders. J Neuroimmune Pharmacol, 2013; 8: 900-20.

[48] Muller R, Kallikorm R, Polluste K, Lember M. Compliance with treatment of rheumatoid arthritis. Rheumatol Int, 2012; 32: 3131-5.

[49] Hou R, Baldwin DS. A neuroimmunological perspective on anxiety disorders. Hum Psychopharmacol, 2012; 27: 6-14.

[50] Dowlati Y, Herrmann N, Swardfager W, Liu H, Sham L, Reim EK, Lanctot KL. A meta-analysis of cytokines in major depression. Biol Psychiatry, 2010; 67: 446-57.

[51] Musselman DL, Miller AH, Porter MR, Manatunga A, Gao F, Penna S, Pearce BD, Landry J, Glover S, McDaniel JS, Nemeroff $\mathrm{CB}$. Higher than normal plasma interleukin-6 concentrations in cancer patients with depression: preliminary findings. Am J Psychiatry, 2001; 158: 1252-7

[52] Danner M, Kasl SV, Abramson JL, Vaccarino V. Association between depression and elevated C-reactive protein. Psychosom Med, 2003; 65: 347-56.

[53] Lanquillon S, Krieg JC, Bening-Abu-Shach U, Vedder H. Cytokine production and treatment response in major depressive disorder. Neuropsychopharmacology, 2000; 22: 370-9.

[54] Tuglu C, Kara SH, Caliyurt O, Vardar E, Abay E. Increased serum tumor necrosis factor-alpha levels and treatment response in major depressive disorder. Psychopharmacology (Berl), 2003; 170: 42933.

[55] Glaser R, Robles TF, Sheridan J, Malarkey WB, Kiecolt-Glaser JK. Mild depressive symptoms are associated with amplified and prolonged inflammatory responses after influenza virus vaccination in older adults. Arch Gen Psychiatry, 2003; 60: 1009-14.

[56] Dellagioia N, Devine L, Pittman B, Hannestad J. Bupropion pretreatment of endotoxin-induced depressive symptoms. Brain Behav Immun, 2013; 31: 197-204.

[57] O'Connor JC, Andre C, Wang Y, Lawson MA, Szegedi SS, Lestage J, Castanon N, Kelley KW, Dantzer R. Interferon-gamma and tumor necrosis factor-alpha mediate the upregulation of indoleamine 2,3-dioxygenase and the induction of depressive-like behavior in mice in response to bacillus Calmette-Guerin. J Neurosci, 2009; 29: 4200-9.

[58] Mendlewicz J, Kriwin P, Oswald P, Souery D, Alboni S, Brunello N. Shortened onset of action of antidepressants in major depression using acetylsalicylic acid augmentation: a pilot open-label study. Int Clin Psychopharmacol, 2006; 21: 227-31.

[59] Muller N, Schwarz MJ, Dehning S, Douhe A, Cerovecki A, Goldstein-Muller B, Spellmann I, Hetzel G, Maino K, Kleindienst N, Moller HJ, Arolt V, Riedel M. The cyclooxygenase-2 inhibitor celecoxib has therapeutic effects in major depression: results of a double-blind, randomized, placebo controlled, add-on pilot study to reboxetine. Mol Psychiatry, 2006; 11: 680-4.

[60] Martino M, Rocchi G, Escelsior A, Fornaro M. Immunomodulation Mechanism of Antidepressants: Interactions between Serotonin/Norepinephrine Balance and Th1/Th2 Balance. Curr Neuropharmacol, 2012; 10: 97-123.

[61] Antonioli M, Rybka J, Carvalho LA. Neuroimmune endocrine effects of antidepressants. Neuropsychiatr Dis Treat, 2012; 8: 6583.

[62] Baharav E, Bar-Yehuda S, Madi L, Silberman D, Rath-Wolfson L, Halpren M, Ochaion A, Weinberger A, Fishman P. Antiinflammatory effect of A3 adenosine receptor agonists in murine autoimmune arthritis models. J Rheumatol, 2005; 32: 469-76.

[63] Yuan XQ, Qiu G, Liu XJ, Liu S, Wu Y, Wang X, Lu T. Fluoxetine promotes remission in acute experimental autoimmune encephalomyelitis in rats. Neuroimmunomodulation, 2012; 19: 201-8.

[64] Krishnadas R, Cavanagh J. Sustained remission of rheumatoid arthritis with a specific serotonin reuptake inhibitor antidepressant: a case report and review of the literature. J Med Case Rep, 2011; 5: 112.

[65] Bouhuys AL, Flentge F, Oldehinkel AJ, van den Berg MD. Potential psychosocial mechanisms linking depression to immune function in elderly subjects. Psychiatry Res, 2004; 127: 237-45.

[66] Tyring S, Gottlieb A, Papp K, Gordon K, Leonardi C, Wang A Lalla D, Woolley M, Jahreis A, Zitnik R, Cella D, Krishnan R. Etanercept and clinical outcomes, fatigue, and depression in psoriasis: double-blind placebo-controlled randomised phase III trial. Lancet, 2006; 367: 29-35. 
[67] Raison CL, Capuron L, Miller AH. Cytokines sing the blues: inflammation and the pathogenesis of depression. Trends Immunol, 2006; 27: 24-31

[68] Raison CL, Miller AH. When not enough is too much: the role of insufficient glucocorticoid signaling in the pathophysiology of stress-related disorders. Am J Psychiatry, 2003; 160: 1554-65.

[69] Claes SJ. CRH, stress, and major depression: a psychobiological interplay. Vitam Horm, 2004; 69: 117-50

[70] Barden N. Implication of the hypothalamic-pituitary-adrenal axis in the physiopathology of depression. J Psychiatry Neurosci, 2004; 29: $185-93$.

[71] Miller GE, Cohen S, Ritchey AK. Chronic psychological stress and the regulation of pro-inflammatory cytokines: a glucocorticoidresistance model. Health Psychol, 2002; 21: 531-41.

[72] Davis MC, Zautra AJ, Younger J, Motivala SJ, Attrep J, Irwin MR. Chronic stress and regulation of cellular markers of inflammation in rheumatoid arthritis: implications for fatigue. Brain Behav Immun, 2008; 22: 24-32.

[73] Peiffer A, Veilleux S, Barden N. Antidepressant and other centrally acting drugs regulate glucocorticoid receptor messenger RNA levels in rat brain. Psychoneuroendocrinology, 1991; 16: 505-15.

[74] Pariante CM, Miller AH. Glucocorticoid receptors in major depression: relevance to pathophysiology and treatment. Biol Psychiatry, 2001; 49: 391-404.

[75] Hallam KT, Smith DI, Berk M. Differences between subjective and objective assessments of the utility of Electroconvulsive therapy in patients with bipolar and unipolar depression. J Affect Disord, 2009; $112: 212-8$

[76] Juruena MF, Pariante CM, Papadopoulos AS, Poon L, Lightman S, Cleare AJ. Prednisolone suppression test in depression: prospective study of the role of HPA axis dysfunction in treatment resistance. Br J Psychiatry, 2009; 194: 342-9.

[77] Kalyoncu U, Dougados M, Daures JP, Gossec L. Reporting of patient-reported outcomes in recent trials in rheumatoid arthritis: a systematic literature review. Ann Rheum Dis, 2009; 68: 183-90.

[78] Gossec L, Dougados M, Rincheval N, Balanescu A, Boumpas DT, Canadelo S, Carmona L, Daures JP, de Wit M, Dijkmans BA, Englbrecht M, Gunendi Z, Heiberg T, Kirwan JR, Mola EM, Matucci-Cerinic M, Otsa K, Schett G, Sokka T, Wells GA, Aanerud GJ, Celano A, Dudkin A, Hernandez C, Koutsogianni K, Akca FN, Petre AM, Richards P, Scholte-Voshaar M, Von Krause G, Kvien TK. Elaboration of the preliminary Rheumatoid Arthritis Impact of Disease (RAID) score: a EULAR initiative. Ann Rheum Dis, 2009; 68: 1680-5.

[79] Gossec L, Paternotte S, Aanerud GJ, Balanescu A, Boumpas DT, Carmona L, de Wit M, Dijkmans BA, Dougados M, Englbrecht M, Gogus F, Heiberg T, Hernandez C, Kirwan JR, Mola EM, Cerinic MM, Otsa K, Schett G, Scholte-Voshaar M, Sokka T, von Krause G, Wells GA, Kvien TK. Finalisation and validation of the rheumatoid arthritis impact of disease score, a patient-derived composite measure of impact of rheumatoid arthritis: a EULAR initiative. Ann Rheum Dis, 2011; 70: 935-42.

[80] Wolfe F, Michaud K, Li T. Sleep disturbance in patients with rheumatoid arthritis: evaluation by medical outcomes study and visual analog sleep scales. J Rheumatol, 2006; 33: 1942-51.

[81] Kojima M, Kojima T, Ishiguro N, Oguchi T, Oba M, Tsuchiya H, Sugiura F, Furukawa TA, Suzuki S, Tokudome S. Psychosocial factors, disease status, and quality of life in patients with rheumatoid arthritis. J Psychosom Res, 2009; 67: 425-31.

[82] Klauenberg S, Maier C, Assion HJ, Hoffmann A, Krumova EK, Magerl W, Scherens A, Treede RD, Juckel G. Depression and changed pain perception: hints for a central disinhibition mechanism. Pain, 2008; 140: 332-43.

[83] Bardin L, Malfetes N, Newman-Tancredi A, Depoortere R. Chronic restraint stress induces mechanical and cold allodynia, and enhances inflammatory pain in rat: Relevance to human stressassociated painful pathologies. Behav Brain Res, 2009; 205: 360-6.

[84] Rosenberger PH, Kerns R, Jok1 P, Ickovics JR. Mood and attitude predict pain outcomes following arthroscopic knee surgery. Ann Behav Med, 2009; 37: 70-6.

[85] Wolfe F. A reappraisal of HAQ disability in rheumatoid arthritis. Arthritis Rheum, 2000; 43: 2751-61.

[86] Katz PP, Yelin EH. Activity loss and the onset of depressive symptoms: do some activities matter more than others? Arthritis Rheum, 2001; 44: 1194-202.
[87] Pollard LC, Choy EH, Gonzalez J, Khoshaba B, Scott DL. Fatigue in rheumatoid arthritis reflects pain, not disease activity. Rheumatology (Oxford), 2006; 45: 885-9.

[88] Belza BL, Henke CJ, Yelin EH, Epstein WV, Gilliss CL. Correlates of fatigue in older adults with rheumatoid arthritis. Nurs Res, 1993; 42: 93-9.

[89] Chauffier K, Salliot C, Berenbaum F, Sellam J. Effect of biotherapies on fatigue in rheumatoid arthritis: a systematic review of the literature and meta-analysis. Rheumatology (Oxford), 2012; 51: 60-

[90] Rupp I, Boshuizen HC, Jacobi CE, Dinant HJ, van den Bos GA Impact of fatigue on health-related quality of life in rheumatoid arthritis. Arthritis Rheum, 2004; 51: 578-85

[91] Wolfe F, Michaud K. Fatigue, rheumatoid arthritis, and anti-tumo necrosis factor therapy: an investigation in 24,831 patients. Rheumatol, 2004; 31: 2115-20.

[92] Huyser BA, Parker JC, Thoreson R, Smarr KL, Johnson JC, Hoffman R. Predictors of subjective fatigue among individuals with rheumatoid arthritis. Arthritis Rheum, 1998; 41: 2230-7.

[93] Ozcetin A, Ataoglu S, Kocer E, Yazici S, Yildiz O, Ataoglul A Icmeli C. Effects of depression and anxiety on quality of life of patients with rheumatoid arthritis, knee osteoarthritis and fibromyalgia syndrome. West Indian Med J, 2007; 56: 122-9.

[94] Tander B, Cengiz K, Alayli G, Ilhanli I, Canbaz S, Canturk F. A comparative evaluation of health related quality of life and depression in patients with fibromyalgia syndrome and rheumatoid arthritis. Rheumatol Int, 2008; 28: 859-65.

[95] Persson LO, Berglund K, Sahlberg D. Psychological factors in chronic rheumatic diseases--a review. The case of rheumatoid arthritis, current research and some problems. Scand J Rheumatol, 1999; 28: 137-44.

[96] Power JD, Perruccio AV, Badley EM. Pain as a mediator of sleep problems in arthritis and other chronic conditions. Arthritis Rheum, 2005; 53: 911-9.

[97] Lee YC, Chibnik LB, Lu B, Wasan AD, Edwards RR, Fossel AH, Helfgott SM, Solomon DH, Clauw DJ, Karlson EW. The relationship between disease activity, sleep, psychiatric distress and pain sensitivity in rheumatoid arthritis: a cross-sectional study. Arthritis Res Ther, 2009; 11: R160.

[98] Luyster FS, Chasens ER, Wasko MC, Dunbar-Jacob J. Sleep quality and functional disability in patients with rheumatoid arthritis. J Clin Sleep Med, 2011; 7: 49-55.

[99] Nicassio PM, Wallston KA. Longitudinal relationships among pain, sleep problems, and depression in rheumatoid arthritis. J Abnorm Psychol, 1992; 101: 514-20

[100] Moldofsky H. Rheumatic manifestations of sleep disorders. Curr Opin Rheumatol, 2010; 22: 59-63.

[101] Folkman S, Moskowitz JT. Coping: pitfalls and promise. Annu Rev Psychol, 2004; 55: 745-74

[102] Connor-Smith JK, Flachsbart C. Relations between personality and coping: a meta-analysis. J Pers Soc Psychol, 2007; 93: 1080-107.

[103] Covic T, Adamson B, Hough M. The impact of passive coping on rheumatoid arthritis pain. Rheumatology (Oxford), 2000; 39: 102730.

[104] Treharne GJ, Lyons AC, Booth DA, Kitas GD. Psychological wellbeing across 1 year with rheumatoid arthritis: coping resources as buffers of perceived stress. Br J Health Psychol, 2007; 12: 323-45.

[105] Newman S, Mulligan K. The psychology of rheumatic diseases. Baillieres Best Pract Res Clin Rheumatol, 2000; 14: 773-86.

[106] Ramjeet J, Koutantji M, Barrett EM, Scott DG. Coping and psychological adjustment in recent-onset inflammatory polyarthritis: the role of gender and age. Rheumatology (Oxford), 2005; 44: 1166-8.

[107] Sturgeon JA, Zautra AJ. State and trait pain catastrophizing and emotional health in rheumatoid arthritis. Ann Behav Med, 2013 45: 69-77.

[108] Edwards RR, Cahalan C, Mensing G, Smith M, Haythornthwaite JA. Pain, catastrophizing, and depression in the rheumatic diseases. Nat Rev Rheumatol, 2011; 7: 216-24.

[109] Marcenaro M, Prete C, Badini A, Sulli A, Magi E, Cutolo M. Rheumatoid arthritis, personality, stress response style, and coping with illness. A preliminary survey. Ann N Y Acad Sci, 1999; 876: 419-25.

[110] Zeidner M aa, Saklofske DHZ, M., \&amp; Saklofske, D.H. Adaptive and maladaptive coping.Handbook of Coping: Theory, Research and Applications. John Wiley: New York 1996. 
[111] Crisson JE, Keefe FJ. The relationship of locus of control to pain coping strategies and psychological distress in chronic pain patients. Pain, 1988; 35: 147-54

[112] Gustafsson M, Gaston-Johansson F. Pain intensity and health locus of control: a comparison of patients with fibromyalgia syndrome and rheumatoid arthritis. Patient Educ Couns, 1996; 29: 179-88.

[113] Cross MJ, March LM, Lapsley HM, Byrne E, Brooks PM. Patient self-efficacy and health locus of control: relationships with health status and arthritis-related expenditure. Rheumatology (Oxford), 2006; 45: 92-6.

[114] Knittle KP, De Gucht V, Hurkmans EJ, Vlieland TP, Peeters AJ, Ronday HK, Maes S. Effect of self-efficacy and physical activity goal achievement on arthritis pain and quality of life in patients with rheumatoid arthritis. Arthritis Care Res (Hoboken), 2011; 63: 1613-9.

[115] Bussing A, Michalsen A, Balzat HJ, Grunther RA, Ostermann T, Neugebauer EA, Matthiessen PF. Are spirituality and religiosity resources for patients with chronic pain conditions? Pain Med, 2009; 10: 327-39.

[116] Lin WC, Gau ML, Lin HC, Lin HR. Spiritual well-being in patients with rheumatoid arthritis. J Nurs Res, 2011; 19: 1-12.

[117] Tillmann T, Krishnadas R, Cavanagh J, Petrides K. Possible rheumatoid arthritis subtypes in terms of rheumatoid factor, depression, diagnostic delay and emotional expression: an exploratory casecontrol study. Arthritis Res Ther, 2013; 15: R45.

[118] Smolen JS. Efficacy and safety of the new DMARD leflunomide: comparison to placebo and sulfasalazine in active rheumatoid arthritis. Scand J Rheumatol Suppl, 1999; 112: 15-21.

[119] Lipsky PE, van der Heijde DM, St Clair EW, Furst DE, Breedveld FC, Kalden JR, Smolen JS, Weisman M, Emery P, Feldmann M, Harriman GR, Maini RN. Infliximab and methotrexate in the treatment of rheumatoid arthritis. Anti-Tumor Necrosis Factor Trial in Rheumatoid Arthritis with Concomitant Therapy Study Group. N Engl J Med, 2000; 343: 1594-602.

[120] Zhang W, Robertson J, Jones AC, Dieppe PA, Doherty M. The placebo effect and its determinants in osteoarthritis: meta-analysis of randomised controlled trials. Ann Rheum Dis, 2008; 67: 171623.

[121] Kaptchuk TJ. The placebo effect in alternative medicine: can the performance of a healing ritual have clinical significance? Ann Intern Med, 2002; 136: 817-25.

[122] Weinblatt ME, Kavanaugh A, Genovese MC, Musser TK, Grossbard EB, Magilavy DB. An oral spleen tyrosine kinase (Syk) inhibitor for rheumatoid arthritis. N Engl J Med, 2010; 363: 1303-12.

[123] Sokka T, Kautiainen H, Pincus T, Toloza S, da Rocha Castelar Pinheiro $G$, Lazovskis $J$, Hetland ML, Peets $T$, Immonen $K$, Maillefert JF, Drosos AA, Alten R, Pohl C, Rojkovich B, Bresnihan B, Minnock P, Cazzato M, Bombardieri S, Rexhepi S, Rexhepi M, Andersone D, Stropuviene S, Huisman M, Sierakowski S, Karateev D, Skakic V, Naranjo A, Baecklund E, Henrohn D, Gogus F, Badsha H, Mofti A, Taylor P, McClinton C, Yazici Y. Disparities in rheumatoid arthritis disease activity according to gross domestic product in 25 countries in the QUEST-RA database. Ann Rheum Dis, 2009; 68: 1666-72.

[124] Vase L, Riley JL, 3rd, Price DD. A comparison of placebo effects in clinical analgesic trials versus studies of placebo analgesia. Pain, 2002; 99: 443-52.

[125] Faria V, Fredrikson M, Furmark T. Imaging the placebo response: a neurofunctional review. Eur Neuropsychopharmacol, 2008; 18: 473-85.

[126] Meissner K, Bingel U, Colloca L, Wager TD, Watson A, Flaten MA. The placebo effect: advances from different methodological approaches. J Neurosci, 2011; 31: 16117-24.

[127] Papadopoulos D, Mitsikostas DD. A meta-analytic approach to estimating nocebo effects in neuropathic pain trials. J Neurol, 2012; 259: 436-47.

[128] Di Blasi Z, Harkness E, Ernst E, Georgiou A, Kleijnen J. Influence of context effects on health outcomes: a systematic review. Lancet, 2001; 357: 757-62.

[129] Odegard S, Finset A, Mowinckel P, Kvien TK, Uhlig T. Pain and psychological health status over a 10 -year period in patients with recent onset rheumatoid arthritis. Ann Rheum Dis, 2007; 66: 1195201.

[130] Bremmer MA, Beekman AT, Deeg DJ, Penninx BW, Dik MG, Hack CE, Hoogendijk WJ. Inflammatory markers in late-life de- pression: results from a population-based study. J Affect Disord, 2008; 106: 249-55.

[131] Bijlsma JW, Huiskes CJ, Kraaimaat FW, Vanderveen MJ, HuberBruning O. Relation between patients' own health assessment and clinical and laboratory findings in rheumatoid arthritis. J Rheumatol, 1991; 18: 650-3.

[132] Margaretten M, Yelin E, Imboden J, Graf J, Barton J, Katz P, Julian L. Predictors of depression in a multiethnic cohort of patients with rheumatoid arthritis. Arthritis Rheum, 2009; 61: 1586-91.

[133] Ho RC, Fu EH, Chua AN, Cheak AA, Mak A. Clinical and psychosocial factors associated with depression and anxiety in Singaporean patients with rheumatoid arthritis. Int J Rheum Dis, 2011; 14: 37-47.

[134] Tuncay R, Eksioglu E, Cakir B, Gurcay E, Cakci A. Factors affecting drug treatment compliance in patients with rheumatoid arthritis. Rheumatol Int, 2007; 27: 743-6.

[135] Bendtsen P, Akerlind I, Hornquist JO. Pharmacological intervention in older patients with rheumatoid arthritis. Quality of life aspects. Drugs Aging, 1995; 7: 338-46.

[136] DiMatteo MR, Lepper HS, Croghan TW. Depression is a risk factor for noncompliance with medical treatment: meta-analysis of the effects of anxiety and depression on patient adherence. Arch Intern Med, 2000; 160: 2101-7.

[137] Brus H, van de Laar M, Taal E, Rasker J, Wiegman O. Compliance in rheumatoid arthritis and the role of formal patient education. Semin Arthritis Rheum, 1997; 26: 702-10.

[138] Garcia-Gonzalez A, Richardson M, Garcia Popa-Lisseanu M, Cox V, Kallen MA, Janssen N, Ng B, Marcus DM, Reveille JD, SuarezAlmazor ME. Treatment adherence in patients with rheumatoid arthritis and systemic lupus erythematosus. Clin Rheumatol, 2008; 27: 883-9.

[139] Kumar K, Gordon C, Toescu V, Buckley CD, Horne R, Nightingale PG, Raza K. Beliefs about medicines in patients with rheumatoid arthritis and systemic lupus erythematosus: a comparison between patients of South Asian and White British origin. Rheumatology (Oxford), 2008; 47: 690-7.

[140] Savard M. Bridging the communication gap between physicians and their patients with physical symptoms of depression. Prim Care Companion J Clin Psychiatry, 2004; 6: 17-24.

[141] Porter LS, Keefe FJ, Wellington C, de Williams A. Pain communication in the context of osteoarthritis: patient and partner selfefficacy for pain communication and holding back from discussion of pain and arthritis-related concerns. Clin J Pain, 2008; 24: 662-8.

[142] Keefe FJ, Shelby RA, Somers TJ. Catastrophizing and pain coping: moving forward. Pain, 2010; 149: 165-6.

[143] Kool MB, van Middendorp H, Boeije HR, Geenen R. Understanding the lack of understanding: invalidation from the perspective of the patient with fibromyalgia. Arthritis Rheum, 2009; 61: 1650-6.

[144] Gleason ME, Iida M, Bolger N, Shrout PE. Daily supportive equity in close relationships. Pers Soc Psychol Bull, 2003; 29: 1036-45.

[145] Montoya P, Larbig W, Braun C, Preissl H, Birbaumer N. Influence of social support and emotional context on pain processing and magnetic brain responses in fibromyalgia. Arthritis Rheum, 2004; 50: 4035-44.

[146] Penninx BW, van Tilburg T, Deeg DJ, Kriegsman DM, Boeke AJ, van Eijk JT. Direct and buffer effects of social support and persona coping resources in individuals with arthritis. Soc Sci Med, 1997; 44: 393-402.

[147] Yazici Y, Abramson SB. Rheumatoid arthritis treatment and monitoring of outcomes--where are we [corrected] in 2007? Bull NYU Hosp Jt Dis, 2007; 65: 300-5.

[148] Barton JL, Trupin L, Schillinger D, Gansky SA, Tonner C, Margaretten M, Chernitskiy V, Graf J, Imboden J, Yelin E. Racial and ethnic disparities in disease activity and function among persons with rheumatoid arthritis from university-affiliated clinics. Arthritis Care Res (Hoboken), 2011; 63: 1238-46.

[149] Bradley LA, Young LD, Anderson KO, Turner RA, Agudelo CA, McDaniel LK, Pisko EJ, Semble EL, Morgan TM. Effects of psychological therapy on pain behavior of rheumatoid arthritis patients. Treatment outcome and six-month followup. Arthritis Rheum, 1987; 30: 1105-14.

[150] Parker JC, Smarr KL, Slaughter JR, Johnston SK, Priesmeyer ML, Hanson KD, Johnson GE, Hewett JE, Irvin WS, Komatireddy GR, Walker SE. Management of depression in rheumatoid arthritis: a combined pharmacologic and cognitive-behavioral approach. Arthritis Rheum, 2003; 49: 766-77. 
[151] Astin JA, Beckner W, Soeken K, Hochberg MC, Berman B. Psychological interventions for rheumatoid arthritis: a meta-analysis of randomized controlled trials. Arthritis Rheum, 2002; 47: 291-302.

[152] Dixon KE, Keefe FJ, Scipio CD, Perri LM, Abernethy AP. Psychological interventions for arthritis pain management in adults: a meta-analysis. Health Psychol, 2007; 26: 241-50.

[153] Sharpe L, Allard S, Sensky T. Five-year followup of a cognitivebehavioral intervention for patients with recently-diagnosed rheumatoid arthritis: effects on health care utilization. Arthritis Rheum, 2008; 59: 311-6.

[154] Vriezekolk JE, Eijsbouts AM, van Lankveld WG, Beenackers H, Geenen R, van den Ende CH. An acceptance-oriented cognitivebehavioral therapy in multimodal rehabilitation: A pre-post test evaluation in highly distressed patients with rheumatic diseases. Patient Educ Couns, 2013; 91: 357-63.

[155] Doherty M, Dieppe P. The "placebo" response in osteoarthritis and its implications for clinical practice. Osteoarthritis Cartilage, 2009; 17: 1255-62.

[156] McDermott MM, Schmitt B, Wallner E. Impact of medication nonadherence on coronary heart disease outcomes. A critical review. Arch Intern Med, 1997; 157: 1921-9.

[157] Irvine J, Baker B, Smith J, Jandciu S, Paquette M, Cairns J, Connolly S, Roberts R, Gent M, Dorian P. Poor adherence to placebo or amiodarone therapy predicts mortality: results from the CAMIAT study. Canadian Amiodarone Myocardial Infarction Arrhythmia Trial. Psychosom Med, 1999; 61: 566-75.

[158] Gettings L. Psychological well-being in rheumatoid arthritis: a review of the literature. Musculoskeletal Care, 2010; 8: 99-106.

[159] Iversen MD, Hammond A, Betteridge N. Self-management of rheumatic diseases: state of the art and future perspectives. Ann Rheum Dis, 2010; 69: 955-63.

[160] Bijsterbosch J, Scharloo M, Visser AW, Watt I, Meulenbelt I, Huizinga TW, Kaptein AA, Kloppenburg M. Illness perceptions in patients with osteoarthritis: change over time and association with disability. Arthritis Rheum, 2009; 61: 1054-61.

[161] Ryan RM, Deci EL. Self-determination theory and the facilitation of intrinsic motivation, social development, and well-being. Am Psychol, 2000; 55: 68-78.

[162] Rollnick S MW, Butler CC. Motivational interviewing in health care. Helping Patients change bahavior. 2008. The Guilford Press; $1^{\text {st }}$ edition.
[163] Hawks SR, Hull ML, Thalman RL, Richins PM. Review of spiritual health: definition, role, and intervention strategies in health promotion. Am J Health Promot, 1995; 9: 371-8.

[164] Thieme K, Flor H, Turk DC. Psychological pain treatment in fibromyalgia syndrome: efficacy of operant behavioural and cognitive behavioural treatments. Arthritis Res Ther, 2006; 8: R121.

[165] Keefe FJ, Van Horn Y. Cognitive-behavioral treatment of rheumatoid arthritis pain: maintaining treatment gains. Arthritis Care Res, 1993; 6: 213-22.

[166] Brus HL, Taal E, van de Laar MA, Rasker JJ, Wiegman O. Patient education and disease activity: a study among rheumatoid arthritis patients. Arthritis Care Res, 1997; 10: 320-4.

[167] de Klerk E, van der Heijde D, Landewe R, van der Tempel H, van der Linden S. The compliance-questionnaire-rheumatology compared with electronic medication event monitoring: a validation study. J Rheumatol, 2003; 30: 2469-75.

[168] Bandura A, Adams NE, Beyer J. Cognitive processes mediating behavioral change. J Pers Soc Psychol, 1977; 35: 125-39.

[169] Martin LR, Williams SL, Haskard KB, Dimatteo MR. The challenge of patient adherence. Ther Clin Risk Manag, 2005; 1: 189-99.

[170] Jin J, Sklar GE, Min Sen Oh V, Chuen Li S. Factors affecting therapeutic compliance: A review from the patient's perspective. Ther Clin Risk Manag, 2008; 4: 269-86.

[171] RA. E. Poor adherence to medication in adults with rheumatoid arthritis - Reasons and solutions. Disease Management \& Health Outcomes 2008;16:13-29. 2008.

[172] Kool MB, van Middendorp H, Lumley MA, Schenk Y, Jacobs JW, Bijlsma JW, Geenen R. Lack of understanding in fibromyalgia and rheumatoid arthritis: the Illness Invalidation Inventory (3*I). Ann Rheum Dis, 2010; 69: 1990-5.

[173] RA. E. Poor adherence to medication in adults with rheumatoid arthritis: reasons and solutions. Dis Manage Health Outcomes. 2008; 16: 13-29.

[174] Sanderson T, Kirwan J. Patient-reported outcomes for arthritis: time to focus on personal life impact measures? Arthritis Rheum, 2009; 61: 1-3.

[175] Sanderson TC, Hewlett SE, Flurey C, Dures E, Richards P, Kirwan JR. The impact triad (severity, importance, self-management) as a method of enhancing measurement of personal life impact of rheumatic diseases. In: ed.^eds., J Rheumatol: Canada, 2011; pp. $191-4$. 